\title{
Criteria for assessing the professional qualities of a forensic expert in the context of improving Russian legal proceedings
}

\author{
Roman Zatona ${ }^{1,2}$ and Natalia Ryabko ${ }^{1,3, *}$ \\ ${ }^{1}$ Don State Technical University, Rostov-on-don, Russia \\ ${ }^{2}$ Rostov State Transport University, Rostov-on-don, Russia \\ ${ }^{3}$ Rostov State University of Economics, Rostov-on-don, Russia
}

\begin{abstract}
It is difficult to overestimate the importance of forensic expertise for resolving issues that arise during the consideration of criminal, civil, administrative and arbitration cases. It is frequently the level of professionalism and expertise of the specialist that determines whether the law is applied correctly and fairly, and whether the criminal is punished as he or she deserves. However, can everyone bear such responsibility? In this paper, the authors attempted to analyze the requirements traditionally imposed on the personality of a forensic expert, as well as to identify criteria for the eligibility of a person to perform such duties.
\end{abstract}

\section{Introduction}

The opinions presented below are not devoid of author's subjectivity, as they are given from the position of an expert practitioner with almost thirty years of experience in forensic work.

The profession of "the expert", like any type of work, requires certain abilities and qualities, specific theoretical knowledge, and practical skills for its implementation. To determine the position of a forensic expert in the system of professions it is necessary to explore the specifics of the professional activity of a forensic expert, create its job profile diagram; determine the requirements that this activity imposes on the personality of a forensic expert; criteria for the professional eligibility of a person to the profession of a forensic expert.

The purpose of drawing up a forensic expert's job profile diagram is to develop an ideal model that should contain a complete qualificational description of a forensic expert from the point of view of the requirements to their professional knowledge, skills, abilities, and personal characteristics. The objective of drawing up and subsequent use of the job profile diagram is to improve expert activities and their quality. In order to achieve these purposes and objectives, it is necessary, first, to investigate the specifics of the expert's professional activity, and second, to determine the requirements that this activity imposes on the mentality and personality of a forensic expert.

\footnotetext{
*Corresponding author: ttriabko@mail.ru
} 
The problems of forensic experts training in the Russian Federation and the development of professionally important qualities of these specialists are a set of theoretical and applied disagreements that have not been resolved so far and some topical issues that have not been properly developed for many years. Despite the fact that the coverage of this issue has been reflected in many scientific publications, and the legislation governing forensic activities is undergoing changes.

Thus, in the $80 \mathrm{~s}$, the Doctor of Laws, Professor A. F. Volynsky pointed out that the problems of training of specialists in the criminal service of the Ministry of Internal Affairs, the Department of Internal Affairs hindered the development of its activities and led to the loss of a significant amount of evidentiary and investigative information, and in general had a negative impact on solving crimes [1]. In the 90s, the Doctor of Laws, Professor V. A. Snetkov noted that the forensic service of the Ministry of Internal Affairs of the USSR requires strengthening in the professional core of highly qualified experts, a significant part of the experts did not possess a full range of forensic techniques, retraining of highly qualified experts was episodic, and with an annual need for 370-400 certified experts, the available potentials of schools allowed to train not more than 150 highly qualified specialists per year [2].

\section{Materials and methods}

In order to consider issues related to determining the job profile diagram of a person's eligibility to exercise the rights, duties and labor functions of a forensic expert, we used not only theoretical views on the features of expert training and the formation of necessary competencies, but also the authors' own practical experience.

Thus, analysis, deduction, and the formal-logical method were used as methodology.

\section{Results}

It has recently been stated in the legal literature that forensic examination is an independent complex legal institution that regulates the activities of a forensic expert in criminal, civil and arbitration proceedings, the legal nature of his conclusions, on the one hand, and the purpose of the examination, on the other hand, as well as the attitude of law enforcement agencies and other participants in the process to the expert and his judgment. Legal regulation as a means of proof determines the requirements that expert activity must meet. The activity of a forensic expert in the Russian Federation is regulated by the Constitution of the Russian Federation, the Federal law "On state forensic expert activity in the Russian Federation", procedural legislation, labor legislation and departmental normative legal acts. Experts of law enforcement agencies are subjected to the relevant legal rules on service and the requirements of disciplinary statutes. In other words, the professional activity of a forensic expert is carried out in the legal field, and the expert, along with specific knowledge in the subject areas, must have knowledge of legal rules (first of all, the rules of procedural law that regulate the use of specific knowledge). The term "specific knowledge" is used in procedural law when determining the grounds for the appointment of an expert examination (article 57 of the Russian Federation Code of Criminal Procedure, article 79 of Code of Civil Procedure of the Russian Federation, 55 of the Arbitration Procedural Code of the Russian Federation). The procedural legislation of Russia, in contrast to the procedural legislation of other States( for example, article 7 of the criminal procedure code of the Republic of Kazakhstan) does not contain explanations as to what knowledge is specific. In the legal literature, some authors distinguish between the terms "knowledge"and "acquirements". At the same time, acquirements are defined as knowledge obtained in the 
course of professional training (theoretical and practical), as a result of which the skills necessary for carrying out a certain type of activity are acquired. Expert research can be defined as a type of acquirement in which a knowledgeable person applies knowledge in a particular field (including skills that are understood in this case as practical knowledge). The result of such research is new knowledge (evidence) on issues that are essential for the administration of justice.

\section{Discussion}

A number of scientific papers, including dissertation studies, are devoted to determining the essence of the term "specific knowledge" through the disclosure of its content. Specific knowledge as a procedural category is defined through general attributes that take into account their content and features, which clearly outline the range of specific knowledge used in the administration of justice. The general characteristics of special knowledge include the possession of such by a limited number of specialists. Such knowledge is not generally known or publicly available. Specific knowledge is acquired in the course of professional training in certain areas of activity and in the course of such activities. The result is the ability of a knowledgeable person to solve certain issues and perform certain actions. The particular features of specific knowledge in the procedural sense should include the fact that they do not cover the professional knowledge of individual participants in legal proceedings, i.e. professional knowledge of the full scope of the rules of procedural and substantive legislations. We can agree with the definition of Lisichenko V. K. and V. V. Tsirkal: "Specfic knowledge is scientific, technical and practical knowledge that is not generally known in court proceedings, acquired as a result of professional training or work in a particular field by a person engaged as a specialist or expert in order to assist the investigator or the court in clarifying the circumstances of the case, giving an judgement on issues that require their application»».

When defining the structure of the forensic examiner's job profile diagram, one of its components, along with professional knowledge, in the content of which we called specific knowledge and knowledge of legal norms, we included skills (abilities).

V. N. Makov's remark that competent persons are required to have not only specific knowledge, but also specific skills for conducting forensic examinations is quite right. This observation is fully proved by practice. Even a forensic expert who has graduated with honors from a university, completed an additional training and received a qualification certificate and the right to conduct examinations in a certain area, passes the stage of professional development in the period up to 5 years. At the same time, he acquires and "grinds" abilities, skills without which it is difficult for him to apply the existing knowledge in his activities, or, much worse, he applies them too boldly and self-confidently. The duration of the stage of professional development is determined both by the personal qualities of the expert, and the ability of colleagues and management of the expert institution to help him. It is appropriate to think of mentoring here, which is traditional for state forensic institutions.

In the legal literature, a skill is defined as "an action formed by repetition, characterized by a high degree of mastery and lack of element-by-element conscious regulation and control" and "a method of performing actions matrixed into muscle memory as a result of multiple repetitions, easily and quickly implemented with minimal mind control". 


\section{Conclusions}

The skills (abilities) required by a forensic expert in their work, as it seems to us, can be divided into several groups:

- private-methodic - the ability to plan work, select and apply research methods and techniques, analyze and assess the identified attributes;

- scientific-research - the ability to identify the problem, determine the object and format, purpose, objectives, research methods; use elements of modern technologies for searching and processing information in their field; organize and conduct an experiment; describe, summarize and finalize the research details;

- communicative and organizational skills;

- professional and personal (observation, attention, depth, flexibility, logical and critical mind, independent thinking, ability to overcome prejudice or bias, etc.).

- moral and legal (high level of legal awareness, law-abiding, etc.).

\section{References}

1. A.F. Volynsky, Expert practice 15, 5-9 (1980)

2. V.A. Snetkov, Expert practice 29, 5-11 (1990) 